Albert Juan Francisco (Orcid ID: 0000-0002-2014-6387)

\title{
The commuting behaviour of self-employed workers: Evidence for Spain
}

Short running title: Excess Commuting and Satisfaction

Juan-Francisco Albert ${ }^{1}$ (corresponding author): Department of Applied Economic Analysis, University of Alicante, Carretera de San Vicente del Raspeig, s/n, 03690 San Vicente del Rașpeig, Alicante (Spain). E-mail address: juan.f.albert@uv.es

José M. Casado-Díaz: Department of Applied Economic Analysis, IEI and IUIT, University

of Alicante, Carretera de San Vicente del Raspeig, s/n, 03690 San Vicente del Raspeig,

Alicante (Spain). E-Mail address: jmcasado@ua.es

Hipólito Simón : Department of Applied Economic Analysis and IEI, University of Alicante, Carretera de San Vicente del Raspeig, s/n, 03690 San Vicente del Raspeig, Alicante (Spain);

IEB, University of Barcelona, Spain; E-mail address: $\underline{\text { hsimon@ua.es }}$

Funding information: This work was supported by ERDF (European Union) and the Ministry of Science, Innovation and Universities (Agencia Estatal de Investigación, IEI) [grant numbers CSO2017-86474-R and CSO2014-55780-C3-2-P (National Plan for Research, Development and Innovation, Spain). J.F. Albert is also grateful for the financial support offered by the

\footnotetext{
${ }^{1}$ Present address: Department of Applied Economics, University of Valencia, Av. dels Tarongers, S/N, 46022 Valencia, Spain.

This article has been accepted for publication and undergone full peer review but has not been through the copyediting, typesetting, pagination and proofreading process which may lead to differences between this version and the Version of Record. Please cite this article as doi: 10.1111/pirs.12469
} 
University of Alicante (program of grants for Master's studies and initiation to the research of the Vice-Rectorate of Research and Knowledge Transfer).

\footnotetext{
Abstract

The aim of the article is to examine the commuting behaviour of self-employed workers in Spain as well as its relationship with satisfaction with job and housing. According to our results although conventional estimations indicate that commuting trips are shorter among the selfemployed, the differences with employees vanish when the potential endogeneity of selfemployment is controlled for. We also show that the job and housing satisfaction levels of the self-employed are less sensitive to commuting than those of the employees, and that in fact no significant effect is observed for relevant segments of the former group, what gives partial support to the theoretical model that we propose where imperfect information problems affect the employees but not the self-employed.
}

Keywords: self-employed, commuting, satisfaction, imperfect information, excess commuting

JEL classification: R20, J64, I3, J28 


\section{Introduction}

The objective of this article is to examine the behaviour pattern of the self-employed against employees in terms of commuting, on the one hand, and the effect of commuting on their levels of satisfaction with job and housing, on the other. Although many previous studies have examined these two particular aspects for the case of the employees, they are much scarcer as regards self-employed workers.

Self-employed workers are a group of particular interest. Previous evidence suggests that the labour-search market of this group is different to that of employees, since they look for places where they can establish a business, rather than for job vacancies (see e.g., Zax, 1991; Holzer, 1994; Stutzer and Frey, 2008). Thus, for them information is likely to be less imperfect and in turn this should lead them to shorter commutes (Giménez-Nadal et al. 2017). Yet, despite the relevance of this phenomenon, only two studies have previously examined the commuting patterns of the self-employed vs. dependent employees in an explicit way. The most recent study in this field is Giménez-Nadal et al. (2018), who analyse the American case and conclude that, after controlling for differences in characteristics, employees' commuting is approximately $17 \%$ higher than that of the self-employed, although such difference varies significantly, however, when workers are disaggregated into different groups according to dimensions such as the size of the area in which they reside. One decade before van Ommeren and van der Straaten (2008) examined this same phenomenon using Dutch data, but in a rather different and suggestive context, since they interpret the difference in commuting times as a measure of the so-called excess commuting, a construct with a long tradition in planning and transportation studies. Excess commuting can be defined as the difference between the time workers actually spend on their journeys between their usual residence and their place of work and the minimum time that could be spent on such journeys given the spatial configuration of homes and jobs (Hamilton 1982), and it is a very relevant phenomenon from the point of view 
of urban design and sustainability. Traditional approaches to this phenomenon have used aggregate data of mobility flows between territorial units to calculate excess commuting based on the unrealistic assumption of perfect substitutability between workers. So much so that the results from the already extensive literature on excess commuting have rarely been used to support real-world policy, something that could be explained by the uncertainties surrounding excess commuting measure (Ma and Banister, 2006). Van Ommeren and van der Straaten (2008) claimed to overcome some of the limitations of such previous studies through the use of individual data, what allowed them to take into account numerous dimensions of heterogeneity within the employed population. The starting point of their approach is the aforementioned possible difference existing between self-employed and employees in terms of information problems. Hence, they assumed that employees face imperfect information problems in the job search process, and must therefore accept longer commutes than the shortest feasible trip, while self-employed individuals do not face such restrictions when they decide the location of their workplaces. Therefore, under this hypothesis, excess commuting can be measured as the difference between the observed commuting times of otherwise comparable employees and self-employed workers. This approach is not of course free from criticism, ${ }^{2}$ since it implicitly assumes an objectionable ceteris paribus condition: if all else is equal the commute of a self-employed person is lower than that of the same person having chosen the same job as employee. However, the relevance of the phenomenon under scrutiny from both the individual and the social points of view makes this approach a very appealing one.

Commuting is a phenomenon with an obvious impact on most people's daily lives, and accordingly the relationship between commuting patterns and individual satisfaction with life or with different dimensions has been empirically examined (see Simón et al., 2018, for a recent

\footnotetext{
${ }^{2}$ We are grateful to an anonymous referee who raised this question.
} 
revision of this literature). A very suggestive way of analysis in this vein was proposed by Stutzer and Frey (2008), who developed a theoretical framework based on the microeconomic theory of location according to which commuting should not affect workers' overall satisfaction, since individuals would only accept longer commuting trips if these were compensated for through higher levels of utility in the workplace and/or in the housing market.

Their own results did not confirm this proposition, however (they found that commuting does have a negative impact on overall satisfaction), what led them to coin the expression "commuting paradox". A number of subsequent studies have used this same framework to gain insight into the complex relationship between these two variables (e.g. Simón et al, 2018). Yet, one relevant gap in these analyses is the exclusion of self-employed workers, which implies that the behaviour of such a relevant group remains unexplored.

The aim of this article is twofold. First, we examine the differences in commuting time between self-employed and employed workers. Second, we focus on the self-employed to provide new empirical evidence of the impact that commuting exerts on their satisfaction levels. In both cases we explicitly recognise the problems associated with the heterogeneity of the working population and accordingly we consider two specific dimensions in which such heterogeneity could be more apparent, geographic location and qualifications. Another contribution of our article is that we propose a simple model that serves as a nexus between the two objectives. This model was constructed based on the assumption that the group of workers that is hypothesised to suffer excess commuting - employees - is the one unable to optimise their combined utility (place of residence and/or place of work) due to problems associated with the existence of imperfect information. Under this hypothesis, employees would be a group for which the location theory as stated by Stutzer and Frey (2008) would not work, and therefore the only class of workers for which commuting could have a negative impact on overall satisfaction. Our empirical analyses are based on Spanish microdata derived from the Survey 
on Quality of Life at Work for the 2007-2010 period, and on a number of different econometric methodologies (OLS, Oaxaca-Blinder decomposition, instrumental variables, and ordered logit). In addressing its two main objectives, the study contributes to the extension of existing knowledge by exploring excess commuting in a Southern European country. This is relevant given the eminently territorial nature of the phenomenon, which is likely to be subject to significant variations between countries, and the absence of comparable studies in other countries within this region.

The article is structured as follows. Section 2 reviews the literature. In Section 3 a theoretical model is developed that combines the article's objectives. Section 4 describes the data used in the empirical analyses, and Section 5 describes and discusses the specific methodologies and derived results. The main conclusions are set out in Section 6.

\section{Literature review}

The negative effects of commuting have been widely documented in the literature. For example, Ross and Zenou (2008) and Van Ommeren and Gutiérrez-i-Puigarnau (2011) point out that commuting leads to increased absenteeism, and authors such as Koslowsky et al. (2013), Evans et al. (2002) and Kahneman et al. (2004), among others, show the negative psychological effects that commuting can induce by raising worker stress levels. Similarly, Gottholmseder et al. (2009), Häming et al. (2009), Hansson et al. (2011), Roberts et al. (2011), Sandow et al. (2014) and Palomino and Sarrias (2019), explore other harmful effects of commuting on health, in dimensions such as obesity, insomnia and increased likelihood of accidents and mortality, among others. Many of these studies point to the existence of variables that moderate these effects. This is the case of, for example, the transport mode used (public transport is less harmful in terms of stress according to authors such as Künn-Nelen, 2015) or the employee's sex (Roberts et al. 2011, show that women suffer most from the negative effects 
of commuting). Moreover, Huinink and Feldhaus (2012), and Sandow (2013) argue that commute length exerts a negative influence on fertility and a positive one on the likelihood of divorce. Bäckström et al. (2016) show that a longer commute increases the cost of participating in the labour market, which may have a particular impact on older workers, causing them to retire at an earlier age. Lastly, Kahneman et al. (2004), and Kahneman and Krueger (2006) show that commuting is one of the daily activities with the most negative impact on individuals' satisfaction of with their personal lives.

This brief sample of articles dealing with the effects of commuting makes it easy to understand why the analysis of excess commuting has occupied a prominent place in diverse research fields in the last decades since it was initially studied by Hamilton (1982). Thus, in the field of regional economics, Hamilton (1982) analysed several cities in the United States and Japan, obtaining results that refute the monocentric model hypothesis, which holds that workers try to find the optimal balance between housing prices and travel costs when deciding on the location of both their residence and their workplace (see the monocentric model by Alonso, 1964; Mills, 1972; and Muth, 1969; as well as the polycentric model by Muller, 1981; Garreau, 1991; and Knox and McCarthy, 2005). The evidence obtained in these studies led to the development of several approaches that attempt to explain the factors and constraints that affect workers' decisions and could therefore cause excess commuting. These include the coexistence of heterogeneous workers in the same residence, which would hinder the simultaneous optimisation of commuting for those workers (Kim, 1995; Buliung and Kanaroglou, 2002; Bergantino and Madio, 2018); the type of housing tenure, since the costs associated with moving house are higher for homeowners than for tenants, and this could lead to longer commutes for the former group (Croper and Gordon, 1991; Crane, 1996); uncertainty about future jobs (Crane 1996); the existence of different incentives associated with using the various modes of transport (Merriman et al. 1995; Van Ommeren et al. 2006); the transaction costs 
associated with changing jobs or homes, and high turnovers, all of them factors that can also lead to longer commuting trips (Giuliano and Small, 1993); factors related to neighbourhood attachment (Ma and Banister, 2006); the influence of other types of daily trips beyond homework commuting (Giuliano and Small, 1993); and imperfect information in the labour market (Rouwendal, 1998; Larsen et al. 2008).

Taking this last point into account, several studies highlight that the existence of imperfect information problems in the labour market results in workers being unable to minimise their commuting time, thereby leading to excess commuting (Weinberg et al. 1981, Zax, 1991; Holzer, 1994). This is the departing point of van Ommeren and van der Straaten (2008), who hypothesise that such problems are only observed in the case of employees and therefore do not affect the self-employed. Their proposition is based on the assumption that self-employed individuals choose their workplaces in contexts where there is perfect information, while employees have to search for job vacancies in a market where there is imperfect information, leading them to accept jobs which do not minimise their commuting time. Accordingly, excess commuting can be defined as the difference in average commuting time between employees and comparable self-employed workers. Although this approach is not free from criticism, it is a valuable attempt to overcome some of the limitations inherent in previous approaches (Ma and Banister, 2006), that have typically used aggregate information on intraregional and interregional commuting flows to calculate the necessary minimum amount of commuting between regions as if workers were assigned to job locations, given the regional distribution of jobs and residences (Van Ommeren and van der Straaten, 2008), what implies assuming perfect substitutability between workers in a framework where the optimal size of the region would therefore be zero -thus inviting to an individual data-based approach.

The first goal of this article is to examine the differences that exist between self-employed workers and employees in terms of their commuting patterns. In this context, we assume that 
Van Ommeren and van der Straaten (2008) propose one of the potential interpretations of such differential commuting. In their study for the Netherlands, van Ommeren and van der Straaten (2008) estimate such difference in the range of $40 \%-60 \%$ while the only other study where the commuting behaviour of self-employed and employed workers is compared, Giménez-Nadal et al. (2018) concludes that commuting time is on average $17 \%$ higher for employees than for the self-employed in the United States.

Self-employed workers are a relevant part of the labour force in all countries. Although its specific behaviour has been much less explored, several studies show that self-employed workers are in many aspects different than employees. For instance, some authors have pointed out that the self-employed are less likely to be constrained in their choices on the labour market (Carrington et al. 1996; Lazear and Moore, 1984; Krueger, 1991). Additionally, Benz and Frey (2008) report that self-employed use to have greater autonomy and more interesting works because they can choose their activities. Frey et al. (2004) and Benz (2007) emphasize this idea pointing out that self-employed have more freedom to choose. In this vein, Hundley (2001) and Nguyen et al. (2003) for the United States, and Benz and Frey (2008) for the UK report that the autonomy of the self-employed positively affects job satisfaction. Overall, this evidence suggests that employed workers derive higher procedural utility from work than employees. Nevertheless, Van den Heuvel and Wooden (1997) show that the self-employed are less satisfied than employees with their income and job security. In this vein, Hundley (2001) suggests the existence of heterogeneity among self-employed, showing that only some self-employed workers have the capacity to adapt their business to changes, so they can feel more secure than employees. In this same vein, several studies state that those self-employed who run a business because of necessity may be less satisfied than those who choose the selfemployment as a consequence of their personal preferences (Cooper and Artz, 1995; Jamal, 1997; Block and Koellinger, 2009; and Carree and Verheul, 2012). Similarly, education has 
been found to negatively affect entrepreneurial satisfaction, since entrepreneurs with higher levels of education may be more likely to overestimate their abilities to run a business and become disappointed (Van den Heuvel and Wooden, 1997; Bradley and Roberts, 2004; Clark and Oswald, 1996).

Connecting with this last point, the second objective of this research is to study the impact of commuting on job and housing satisfaction, following the approach of Simón et al. (2018). In their study, where only employees are considered, these authors use the framework proposed by Stutzer and Frey (2008) to interpret their results. They find that commuting has a negative impact on the satisfaction of Spanish employees in all domains of life, regardless of sex, transport mode or business cycle phase. The findings of Simón et al. (2018) thus refute the hypothesis proposed by Stutzer and Frey (2008) based on the microeconomic theory of location, according to which individuals should choose jobs involving longer commutes only if this is compensated for with better jobs and/or better prospects in the housing market. Therefore, although the commuting itself has a negative impact on well-being, an overall null net effect on satisfaction should be expected. This is a proposition for which the scarce (and geographically focused) empirical evidence available has produced mixed results. Thus, in their study of the German case, Stutzer and Frey (2008) observe that a longer commute is associated with lower levels of satisfaction with life, leading to the conclusion that commuting is an activity which is not compensated for by other mechanisms, constituting what could thus be conceptualised as a "commuting paradox". A later study by Roberts et al. (2011) considers the case of the United Kingdom and shows that the negative effect of commuting on employee satisfaction is observed only in the case of women. The British case is also studied by Dickerson et al. (2014) who, in contrast to previous studies, found evidence that a longer commute has a negative impact on leisure time satisfaction, but not on life satisfaction. Lastly, in his study for Cardiff, Crawley (2014) finds that commuting time has a negative impact on 
job satisfaction regardless of the mode of transport used, with the exception of workers with higher incomes. In a novel approach, this article focuses on the impact of commuting on job and housing satisfaction differentiating between self-employed individuals and employees, providing thus new evidence on the effects of commuting for self-employed workers, a group not considered by the previous literature.

\section{Theoretical model}

The model presented in this section is an extension of the Stutzer and Frey (2008) model, which predicts a balance of utility in the labour and housing markets. The novelty lies in the consideration of transaction costs derived from non-perfect information problems that hinder the optimisation of individual utility.

The equilibrium concept adopted in microeconomic theory consists in the assumption that commuting costs - monetary, psychological or other - are offset in the labour or housing market. That is to say, if an individual accepts a new job that entails a longer time of travel between the place of work and their place of residence, the theory predicts that this new job will compensate them in some way, either in labour terms (for example with a higher salary or better working conditions) and/or through better residential conditions (for example with a lower rent or a better neighbourhood). Note, therefore, that there are multiple combinations of these three elements (commuting, job satisfaction and housing satisfaction) which would be characterised by a compensation relationship among them in the absence of other restrictions or additional costs. The model proposed here incorporates a specific type of additional cost faced by employees when they decide to change or start a new job, associated with the existence of non-perfect information problems. 
Therefore, in this model a worker's utility depends on combinations of the level of well-being at work $\mathrm{l}_{\mathrm{i}}$, commuting time $\mathrm{c}_{\mathrm{i}}$, housing satisfaction $\mathrm{h}_{\mathrm{i}}$, and the utility generated by lower transaction costs $\left(\mathrm{tc}_{\mathrm{i}}\right)$ derived from imperfect information problems.

$$
\mathrm{U}_{\mathrm{i}}=\mathrm{u}\left(\mathrm{l}_{\mathrm{i}}, \mathrm{c}_{\mathrm{i}}, \mathrm{h}_{\mathrm{i}}, \mathrm{tc}_{\mathrm{i}}\right) \quad \mathrm{Vi}
$$

Differentiating the previous equation, we get:

$$
\mathrm{dU}=\frac{\partial u}{\partial l} \mathrm{dl}+\frac{\partial u}{\partial c} \mathrm{dc}+\frac{\partial u}{\partial h} \mathrm{dh}+\frac{\partial u}{\partial t c} \mathrm{dtc}=0
$$

The variation in commuting time implies:

$$
\frac{\partial U}{\partial c}=\frac{\partial u}{\partial l} \frac{\partial l}{\partial c}+\frac{\partial u}{\partial c}+\frac{\partial u}{\partial h} \frac{\partial h}{\partial c}+\frac{\partial u}{\partial t c} \frac{\partial t c}{\partial c}=0
$$

The right-hand side of equation 3 implies that commuting time variations do not have a net effect on a worker's general utility. On the left-hand side, it can be seen that an increase in commuting time could lead to several effects: (1) a marginal increase in job satisfaction derived, for instance, from a higher salary (according to theory, workers would accept a longer commute if that is compensated for by a better job); (2) a marginal gain in housing satisfaction analogous to the previous one; (3) a loss of utility due to all the costs associated with a longer commute, both in financial (travel expenses) and psychological (such as increased stress) terms, and (4) non-perfect information could be offset by a marginal increase in the worker's utility due to the lower costs borne by the worker if they do not need to carry out a more exhaustive job search or deal with such non-perfect information problems.

According to equation (3), the four marginal changes resulting from an increase in commuting must compensate each other so that an overall null effect on utility is observed. If the transaction costs were zero, the fourth effect would not exist, only the other three would operate, and the final outcome would therefore be similar to that traditionally predicted by the microeconomic theory of location and to the version proposed by Stutzer and Frey (2008). In 
the model proposed here, this is the case for self-employed workers, since it is assumed that for this group of workers there are no transaction costs involved. In contrast, it is assumed that transaction costs take positive values in the case of employees due to the existence of imperfect information problems in the job search process. Therefore, according to this model, the selfemployed would be the only group of workers for which longer commutes would be compensated for through improvements in their levels of satisfaction with housing or work, while employees are theoretically least likely to offset the longer travel time with an increase in the utility linked to other spheres.

$$
\text { employees TC }>\text { self-employed } \mathrm{T}=0
$$

\section{Data and variables}

The microdata used in the research have been obtained from the Survey on Quality of Life at Work (Encuesta de Calidad de Vida en el Trabajo; SQLW hereafter), which was annually conducted by the Spanish Ministry of Employment and Social Security between 1999 and 2010. The survey includes information about many personal and socio-economic characteristics, as well as on the objective features of jobs and on workers' perceptions about their working conditions, among other factors, which allows the analysis of workers' wellbeing. Consisting of yearly independent cross-sections, each of which provides information about around 8,000 workers, the survey covers the entire national territory (only the autonomous cities of Ceuta and Melilla were excluded) and is restricted to workers aged 16 and over who reside in family dwellings.

To carry out the empirical analysis in this work, we considered a data pool covering 4 years (2007-2010), made up by 30,920 workers, 25,520 of them employees and 5,400 self-employed.

The choice of the period 2007-2010 is due to the fact that those are the only waves of the SQLW in which the variable commuting is measured continuously in minutes (until the wave 
of 2006 the variable commuting was measured in intervals in the survey). We restricted the sample to those between 16 and 65 years old, whose commutes involved less than 3 hours (excluding only 10 observations). According to the theory of imperfect information in the job search proposed by van Ommeren and van der Straaten (2008), working from home is due to factors such as having a dwelling suitable for working, the type of work carried out, whether the worker lives alone or in a family, and the size of the firm, among others. According to these authors, the decision to work from home is exogenous to the job search process. Therefore, those working from home should be excluded from the analysis to allow a better measurement of the excess commuting derived from imperfect information problems in the job search. Consequently, we exclude in the empirical analysis those individuals working from home. This exclusion, which is a frequent strategy that allows accounting for skewness in the distribution of commuting time, permits estimating the excess commuting in logarithms what in turn allows the comparison with the previous literature. In this case, this implied excluding 437 employee observations (around 2\% of the original sub-sample) and 662 self-employed observations (11\% of the corresponding sub-sample) from the total sample. In any case, in the empirical analysis several robustness tests were conducted including also individuals with zero commuting time (Table A.2 of the Appendix). The main results remained unaltered.

The dependent variable in the first part of the analysis is the logarithm of commuting time, computed in minutes. Considering commuting as travel time instead of using the alternative of distance has the advantage of measuring the cost of travel taking into account the different modes of transport used and issues such as road quality and congestion. It is also accepted as a more reliable measure since people appear to have a better notion of the time spent in their commute than of the distance covered. Whether the individual is an employee or self-employed is measured through a dichotomous variable. The other independent variables comprise individual characteristics (sex, age, and level of education, distinguishing between primary, 
secondary and university education); household characteristics (whether workers live with a partner or have children under 14 , as well as household net monthly income, measured in 9 intervals); municipality size (in three categories: $<50,000 ; 50,000-1,000,000 ;>1,000,000$ inhabitants), and work-related variables such as firm size (three categories: $<10,10-250,>250$ workers); occupation (distinguishing between skilled, semi-skilled and unskilled workers); sector of activity (differentiating between 12 sectors); and the number of weekly working hours. Dummy region and year variables are also included to control for regional and cyclical dimensions.

Part of the empirical analysis is based on instrumental variables techniques, using as an instrument if the individual declares vocational entrepreneurship. This is measured with a dichotomous variable that takes value 1 for those individuals who state they prefer selfemployment status and value 0 for those who declare their preference for working as employees, regardless of their particular current employment situation. This variable allows distinguishing between necessity and vocational entrepreneurship and approximates the workers' real desire to run a business. Interestingly, the proportion of actual self-employed workers with a vocational preference for self-employment is $63 \%$ whilst the proportion of employees with a preference for self-employment is only $22 \%$ (Table A.1), which suggests relevant differences between both collectives in the incidence of vocational entrepreneurship (this phenomenon has been well documented in the Spanish case by Cueto and Pruneda, 2015). On the other hand, for the analysis of satisfaction levels among self-employed workers carried out in the second part of the empirical analysis, satisfaction with work and housing were alternatively used as dependent variables (both variables are measured on a 0-10 scale, where 0 is total dissatisfaction and 10 absolute satisfaction). The descriptives of the full set of variables used in the empirical analysis are included in table A.1 of the Appendix. 


\section{Results}

In short, this section starts by presenting descriptive evidence on the relative patterns of commuting and satisfaction of self-employed workers (subsection 5.1.). Subsequently, the determinants of commuting are examined in subsection 5.2 using three different econometric methodologies (OLS, Oaxaca-Blinder decomposition, and instrumental variables). These techniques allow a throughout examination of the differences in commuting between selfemployed workers and comparable employees with similar observed characteristics. The advantage of the Oaxaca-Blinder decomposition as for OLS is that it provides a decomposition of the raw difference in commuting between self-employed and employees into the characteristics and return components, as well as a detailed decomposition of both components according to the relative influence of each set of individual explanatory variables. In turn, the instrumental variables technique allows controlling for the potential endogeneity of the variable that reflects whether the individual is self-employed. Finally, the determinants of satisfaction in different life domains are examined in subsection 5.3 via ordered logit estimations.

\subsection{Descriptive analysis}

The descriptive evidence (table A.1 of the Appendix) shows that the average commuting trip is shorter for the self-employed group (17.89 minutes) than for employees (22.15 minutes), a pattern already described by van Ommeren and van der Straaten (2008) and Giménez-Nadal et al. (2018). According to these figures the difference in commuting time for Spanish workers is $23.8 \%$, a figure slightly lower than the $30-40 \%$ range estimated by van Ommeren and van der Straaten (2008). When the satisfaction variables are examined, the differences between the selfemployed and the employees appear to be rather low, although satisfaction with both work and housing tends to be slightly higher for self-employed individuals. Regarding the other observed characteristics, table A.1 shows that, on average, self-employed workers include fewer women, tend to be slightly older and less qualified, earn a higher monthly income, work on average 
more hours per week, have a roughly similar annual household income, suffer less from overeducation, have better occupations, work in much smaller firms, and are over-represented in certain sectors (such as retailing and professional and scientific services). Lastly, regarding modes of transport, self-employed use comparatively more certain modes of transport (such as, especially, walking), and comparatively less public modes of transport like bus/metro/train.

\subsection{Determinants of commuting}

5.2.1. OLS

To quantify the differences in commuting times between self-employed and employees the following equation was estimated using ordinary least squares (OLS):

$$
y_{i}=\alpha+\beta_{1} S_{i}+\beta_{2} X_{i}+\beta_{3} F_{i}+\varepsilon_{i}
$$

Where $y_{i}$ represents the logarithm of commuting time for individual $i$; $S_{i}$ is a dichotomous variable that indicates whether the individual $i$ is a self-employed worker; $X_{i}$ is a set of variables that capture individual characteristics (sex, age, nationality, and level of education), household characteristics (living with partner, children, and income level), variables relating to occupation (firm size, occupation, sector of activity, and hours worked per week), and the size of the municipality of residence; $F_{i}$ is a vector of variables that includes region and year fixed effects; and $\varepsilon_{i}$ is the individual error term.

The first column of Table 1 shows the result of the estimation of equation (5). It is observed that commuting increases with education, firm size and the size of the municipality of residence, and that it is lower among women and native workers. Regarding the variable of interest, the coefficient of self-employed variable is negative and statistically significant. Consequently, the difference in commuting time between self-employed and employees in Spain is around $19.5 \%$ (as the dependent variable is logarithmic, the results can be interpreted approximately in percentages), a lower figure than that estimated in the Dutch case by Van 
Ommeren and van der Straaten (2008) (between $40 \%$ and $60 \%$ depending on the database), and rather similar to the $17 \%$ found by Giménez-Nadal et al. (2018) for the United States. A complementary analysis through the inclusion of mode of transport results in an additional reduction of the estimated difference in commuting times to $13.1 \%$ (second column of table 1).

In order to test the robustness of the results, several disaggregated analyses were conducted, distinguishing between diverse groups defined by size of the municipality (three municipal population ranges) of residence and qualification (individuals are classified into three groups according to their qualification level). According with the job search process theory, it could be hypothesized that the employees/self-employed differences in commuting may depend on the municipality size. This hypothesis is explored in the model through the inclusion of interaction effects between different ranges of municipality size and the self-employment condition. As it is expected, the differences in commuting are higher in more populated areas. As a matter of example, such differences reach their highest value in Madrid and Barcelona (the only municipalities in Spain with more than 1 million inhabitants). This is in line with previous results in the literature, given that also in the case of the United States it has been observed that differences in the length of commuting between self-employed and employed workers are positively correlated with the size of the metropolitan statistical areas (GiménezNadal et al. 2018). Table 2 also reports the results obtained when the self-employment variable is interacted with different levels of worker's qualification, showing that the estimated coefficient is higher for workers in more qualified jobs. This result is in line with the definition of excess commuting by van Ommeren and van der Straaten (2008) and with the information problems theory in the job search process. This theory predicts that the employment density of specialized jobs is much lower, thus for them excess commuting should be higher. In the same vein, a robustness test including individuals with zero commuting time was conducted (in this case the dependent variable, commuting time, is not log-transformed). Although the inclusion 
of individuals with zero commuting results in a reduction of the self-employment coefficient, the main results remained unaltered (table A.2 of the Appendix).

\subsubsection{Oaxaca-Blinder decomposition}

Additionally, we conducted a complementary approach to the examination of the determinants of differences in commuting times between self-employed and employees through the use of the Oaxaca-Blinder decomposition technique (Oaxaca, 1973; Blinder, 1973). This approach allows the raw average gap between two collectives in the value of a continuous variable to be broken down into two parts: one that is explained by the average differences between the two groups in terms of observed characteristics (the explained or characteristics component), and a second part that measures the extent to which the coefficients of the characteristics of comparable individuals of the two groups are different (the unexplained or coefficients component). In our case, apart from providing the decomposition of the raw difference in commuting between self-employed and employees in the characteristics and coefficient components, an additional advantage of the Oaxaca-Blinder decomposition compared to OLS is that it provides a detailed decomposition of both components according to the relative influence of each set of independent variables considered.

The estimation strategy starts with the specification of two separate commuting equations for each group:

$$
\begin{aligned}
& Y_{\text {ei }}=X^{\prime}{ }_{\text {ei }} \beta_{\mathrm{e}}+\varepsilon_{\text {ei }}, i=1, \ldots N_{e} \\
& Y_{s i}=X^{\prime}{ }_{\text {si }} \beta_{s}+\varepsilon_{s i}, i=1, \ldots N_{s}
\end{aligned}
$$

Where $e$ refers to employees and $s$ to self-employed workers for each individual $i$; $Y$ is the logarithm of the commuting length; $X$ is the same vector of variables described in section 5.2.1; and $\varepsilon$ is the error term. 
Once the commuting equations for each of the groups had been estimated, the decomposition is expressed by the following equation:

$$
\overline{\mathrm{Y}}_{\mathrm{e}-} \overline{\mathrm{Y}}_{\mathrm{s}}=\left(\bar{X}_{\mathrm{e}}-\bar{X}_{\mathrm{s}}\right) \hat{\beta}_{\mathrm{e}}+\bar{X}_{\mathrm{s}}\left(\hat{\beta}_{\mathrm{e}}-\hat{\beta}_{\mathrm{s}}\right)
$$

According to this equation, the difference in commuting time between the two groups can be broken down into an explained part, which is due to differences in their relevant characteristics, and a coefficients component, which reflects the part of the average differences in commuting that is due to the fact that individuals with similar characteristics behave differently. As is rather usual in this kind of analysis, the returns of the majority group (i.e. employees) are used as the hypothetical non-discriminatory returns structure in the decomposition.

The results of the Oaxaca-Blinder decomposition are shown in Table 3. According to this evidence approximately half ( $45 \%$; 0.157 of around $0.35 \log$ points) of the raw difference in commuting times between self-employed and employees can be explained by the different characteristics of both groups of workers. The detailed results of the characteristics component show that this is due to the smaller average size of the municipalities were self-employed individuals reside and, very especially, to their smaller average firm size. The remaining unexplained part of the raw difference (55\%; 0.195 logarithmic points) captures the magnitude of the lower commuting of observationally similar self-employed workers (note that this figure is analogous to that estimated via OLS in Table 1).

On the other hand, including mode of transport within the set of explanatory variables (second column in Table 2) results also in this case in a relevant reduction of the commuting unexplained differential, given that the coefficient component falls to 0.130 logarithmic points. Hence, when the different modes of transport are included in the analysis, the explained term increases to 0.22 logarithmic points (63\% of the total gap), and differences between self- 
employed and employees in certain modes of transport (very especially walking) turn to explain a relevant part of raw relative differences in commuting times.

Overall, this evidence suggests that although part of the lower commuting times of selfemployed workers in Spain can be explained by their different characteristics (very especially in terms of aspects such as the size of the municipalities where they reside, the size of their firms, or the mode of transports they use) significant differences remain as regards observationally similar employed workers, which suggests a different commuting pattern of both groups. This could, at least to a certain extent, be due to imperfect information problems in the job search process.

\subsubsection{Instrumental Variables}

Selection into self-employment can be an important issue in our estimation strategy, since there are unobserved factors potentially related to both the decision to be self-employed and how much time is spent in daily commuting (Van Ommeren and Van der Straaten, 2008, and Giménez-Nadal et al. 2018). The potential endogeneity of the self-employment variable, something that is confirmed through the conventional tests, can be an important limitation given that, as it is well known, when an explanatory variable is correlated with the error term OLS do not generate consistent estimations of the parameters of interest. Considering that the limitation derived from the potential endogeneity of self-employment cannot be overcome using data panel techniques (given that the SQLW microdata is composed of independent cross-sections for each year), the use of instrumental variables could be an appropriate way of overcoming it.

Accordingly, in this section a model was estimated through instrumental variables using the vocational entrepreneurship variable already described as an instrument. This permit addressing the endogeneity problem in a novel way in the literature. Table 4 shows the results 
of conventional tests, which confirm that the use of instrumental variables is appropriate. Hence, results of the Durbin and Wu-Hausman test were all statistically significant (at the 10 $\%$ significance level), confirming that self-employment is endogenous. On the other hand, the null hypothesis of weak instrument can be rejected because the partial F-statistics met the recommended cut-off and, a result, vocational entrepreneurship seems a relevant instrument. The results of the estimation via instrumental variables show, accordingly, that the coefficient of the self-employed variable is not statistically significant at the usual levels of significance. Hence, in contrast with the results obtained through OLS, this finding suggests that differences between self-employed and similar employees in commuting times could be negligible.

\subsection{Determinants of satisfaction: Ordered logit}

In order to examine the second objective of this research, the impact of commuting on the satisfaction of workers, we assume that the alternatives of the decision-making process implicitly express an order of utility and therefore have an ordinal character, which supports the idea of conducting estimations based on ordered logit or probit models (see MacKerron, 2012, and Dickerson et al. 2014). In such models, the estimated coefficient itself is not relevant and conclusions are drawn through the analysis of its sign and the variables' level of statistical significance.

Under this approach, two different domains of satisfaction, with work and housing, respectively, were considered. The corresponding variables are measured on a 0-10 scale, where 0 is total dissatisfaction and 10 absolute satisfaction. The following approximation of the welfare function was used:

$$
\mathrm{y}_{\mathrm{i}}=\alpha++\beta \mathrm{X}_{\mathrm{i}}+\varepsilon_{\mathrm{i}}
$$

Where $i$ is an individual; $y_{i}$ is the continuous dependent variable that represents the levels of satisfaction in job or housing; $X_{i}$ is a vector of observable characteristics that comprises the 
same variables used in the previous part of the empirical analysis, with the addition of commuting as an explanatory variable; and $\varepsilon_{i}$ is the individual error term.

In this approach, $y_{i}$ can only be observed indirectly, and is assigned ordered values according to the classification of a certain satisfaction segment. This can be expressed as:

$$
\begin{array}{r}
y_{i}=0 \quad \text { if } y^{*} \leq Z(0) \\
y_{i}=j \quad \text { if } Z(j-1)<y^{*}{ }_{i} \leq Z(j)
\end{array}
$$

Where $Z(j)$ are the quantitative thresholds of each satisfaction span. The probability that an individual is in the corresponding segment of satisfaction is given by:

$\operatorname{Pr}\left[y^{*}{ }_{i}=j\right]=\left[1 /\left[1+\exp \left(\beta X_{i}-Z(j)\right)\right]\right]-\left[1 /\left[1+\exp \left(\beta X_{i}-Z(j-1)\right)\right]\right]$

It is therefore possible to determine how the variables included in vector $X_{i}$ affect the likelihood that an individual is located in a segment of the ordinal satisfaction scale. Both the coefficients and the thresholds are estimated through maximum likelihood.

Table 5 shows that when all workers are overall considered commuting exerts a negative impact on satisfaction in the two domains of life examined, and that self-employed do not exhibit different levels of job and housing satisfaction when compared with observationally similar employees. These results are robust, on the other hand, to the inclusion of a much wider set of explanatory variables in the model (table A.3). When the estimation of the determinants of satisfaction is carried out separately for both groups of workers, it is observed that longer commutes are significantly and negatively associated with job and housing satisfaction in both cases (table 6). Accordingly, the so-called commuting paradox is apparently also observed among the self-employed, who seem to be as unable to optimise their global satisfaction by compensating for longer commutes with higher levels of job/housing satisfaction as employees (Simón et al. 2018). 
This result, which is in principle at odds with the theoretical model proposed in section 3, might however hide relevant differences that could emerge if the heterogeneity of self-employed workers was taken into account. Thus, following a similar approach to that adopted in the first part of our analysis, additional estimations examine two relevant dimensions: the characteristics of the geographical space (through the separate consideration of three municipal population ranges) and occupations (which are again classified into three groups according to their qualification level). In contrast with the aggregate analysis, these results (table 7), give partial support to our theoretical model. Thus, intermediate-size municipalities and less qualified occupations are the categories for which the general conclusion holds while for both less populated areas and Spanish largest municipalities (Madrid and Barcelona), and for semiqualified and qualified occupations, the relationship between commuting and satisfaction is not significant. Although such result cannot be considered as giving strong support to the predictions of the theoretical model it does not allow rejecting it for these relevant categories. ${ }^{3}$

\section{Conclusions}

This article has two main objectives. On the one hand, we examine the commuting behaviour of the self-employed vs. employees, in a context where the behaviour of the former group has been much less explored despite its quantitative relevance and the existence of previous evidence suggesting that their search market is likely to have quite specific features. On the other hand, we analyse how commuting affects workers' satisfaction in different domains of life, emphasising the differences between employed and self-employed workers. Regarding the first objective, we argue that a possible interpretation of the difference in commuting length between both groups could be the one proposed by Van Ommeren and van der Straaten (2008),

\footnotetext{
${ }^{3}$ As in the previous subsection, a robustness test including individuals with zero commuting time was conducted. The main results remained unaltered. More details can be found in Table A.4 in the Appendix.
} 
for whom such difference is a measure of excess commuting, based on the assumption that while employees encounter imperfect information problems in their job search (and such problems cause them to make unnecessary longer commutes), the self-employed make more flexible arrangements in the absence of such information problems. Regarding the second objective, we examine the differences experienced by self-employed and employees workers in terms of the effect that commuting exerts on satisfaction according to the reinterpretation of the microeconomic theory of location proposed by Stutzer and Frey (2008). According to that formulation workers should compensate for longer commutes with higher levels of satisfaction in certain domains of their life, and therefore commuting should be negatively linked to e.g. job and housing satisfaction (a result that is not, however, observed in all countries and for all groups of workers, what has been called the commuting paradox). To link both objectives we propose a simple theoretical model according to which the commuting paradox should apply to the group of workers that experience excess commuting (employees), but not to selfemployed individuals, who should be able to maximise their overall utility and for whom no effect of commuting on satisfaction is therefore expected.

Our empirical analysis shows, first, that when estimated through OLS the length of the average commute made by the self-employed workers in Spain is around $19 \%$ lower than that of the comparable employees. When the mode of transport used in such commutes is also controlled for the figure goes down to around 13\%. According to Van Ommeren and van der Straaten (2008) these figures could measure excess commuting in Spain, based on the hypothesis of non-perfect information in the job search process. Although such figures are lower than those estimated using individual data in the Netherlands (Van Ommeren and van der Straaten, 2008) and previous studies of other national cases based on aggregate data (see Ma and Banister, 2006, and Van Ommeren and van der Straaten, 2008), they are in line with a recent analysis of the US case by Gimenez-Nadal et al. (2018). Furthermore, when we consider the heterogeneity 
of workers through disaggregated analyses based on municipality size and qualification, differences in commuting between both groups of workers increase for relevant parts of the occupied and become particularly high in the most populated municipalities (Madrid and Barcelona), and in more qualified occupations. The complementary evidence obtained through the use of the Oaxaca-Blinder decomposition technique confirms in turn that just a part of the observed difference in commuting times between employees and self-employed workers is due to the differences in personal and socioeconomic characteristics among the individuals making up each worker group. This result suggests that there is an unobservable dynamic among employees and self-employed individuals that could at least in part be due to non-perfect information problems and is therefore compatible with the imperfect information assumption in the job search model proposed by van Ommeren and van der Straaten (2008). Finally, in order to deal with the potential endogeneity problem of the self-employed variable, we used instrumental variables with a measure of the attitude of individuals towards vocational entrepreneurship as instrument. In contrast with OLS estimates, the instrumental variables results do not provide statistically significant evidence of the existence of differences in commuting between Spanish self-employed workers and employees. This finding is at odds with the results found in previous studies for other countries and, in the interpretation of Van Ommeren and van der Straaten (2008), suggest that excess commuting would be null. In any case, this result should probably be taken in a cautious way. Although standard tests confirmed the validity of the instrument chosen, the instrumental variable technique itself has both defenders and detractors, what calls for further research considering other cases in order to broaden the base of empirical studies.

With regard to the second objective of this study, we estimated different ordered logit models to examine the effect of commuting on job and housing satisfaction for employed and selfemployed workers. According to our results, commuting exerts a negative impact on both 
domains of satisfaction for both groups of workers. However, the negative effect observed for self-employed seem to be partly due to their heterogeneity. Thus, when dimensions such as municipality size and job's qualification are considered, the evidence gives partial support to the model for most groups of workers (those living in small as well as in the largest municipalities, and those in jobs with medium and high requirements in terms of qualifications). Accordingly, the results of the empirical analysis confirm that the selfemployed are in general more tolerant to commuting than employees, so that for them longer commutes have a less strong negative effect on satisfaction with their job and housing compared with dependent employees. And more relevantly, no significant link exists between commuting and satisfaction with these two dimensions, except for those living in mediumsized areas and those in less-qualified occupations. According to our theoretical model these findings are at least partially compatible with the hypothesis of Van Ommeren and van der Straaten (2008) who state that the shorter duration of commuting among self-employed workers reflects the existence of an excess commuting originating in differences related to search imperfections, based on the assumption that the self-employed minimise their commuting, as they face fewer restrictions in their job search process and have more chances of choosing their workplaces optimally.

To conclude, and with regards to policymaking, the results of our analyses indicate that there might be a room for policies targeted at reducing the length of commute for particular groups of workers and territories, for which commuting lengths are well above the average and could therefore be excessive. Although previous literature suggests that such higher durations could be partially compensated at the individual level in terms of e.g. access to other activities, it seems clear that, set within the sustainable development debate, the resulting aggregate patterns have policy implications. Thus, previous literature on excess commuting suggested that there was a case for potential gains following the adoption of policies to re-orientate workers to more 
adequate locations, so that a job-housing balance policy could serve to alleviate traffic congestion and emissions. Such focused policies should be however carefully formulated and implemented since, as Ma and Banister (2006) warn, policies targeted at reducing the length of the commute for particular groups could disadvantage other workers who are not targeted.

\section{References}

Alonso W (1964) Location and Land Use (MA: Harvard University Press) Cambridge.

Bäckström P, Sandow E, Westerlund O (2016) Commuting and timing of retirement. The Annals of Regional Science 56(1): 125-152.

Benz M (2007) The relevance of procedural utility for economics, in Frey BS Stutzer A: Economics and psychology: a promising new cross-disciplinary field (Mass.: MIT Press) Cambridge.

Benz M, Frey, B S (2008) The value of doing what you like: Evidence from the self-employed in 23 countries. Journal of Economic Behavior \& Organization 68: 445-455.

Bergantino AS, Madio L (2018) Intra- and inter-regional commuting: Assessing the role of wage differentials. Papers in Regional Science 98: 1085- 1114.

Blinder AS (1973) Wage discrimination: Reduced form and structure estimates. Journal of Human Resources 8: 438 - 455.

Block J, Koellinger P (2009) I can't get no satisfaction-Necessity entrepreneurship and procedural utility. Kyklos 62(2): 191-209.

Bradley DE, Roberts JA (2004) Self-employment and job satisfaction: Investigating the role of self-efficacy, depression, and seniority. Journal of Small Business Management 42(1): 37-58. 
Buliung RN, Kanaroglou PS (2002) Commute minimization in the Greater Toronto Area: applying a modified excess commute. Journal of Transport Geography 10: 177-186.

Carree M, Verheul I (2012) What Makes Entrepreneurs Happy? Determinants of Satisfaction Among Founders. Journal of Happiness Studies 13(2): 371-387.

Carrington WJ, McCue K, Pierce B (1996) The role of employer/employee interactions in labor market cycles: evidence from the self-employed. Journal of Labor Economics 14 (4): 571-602.

Clark AE, Oswald AJ (1996) Satisfaction and comparison income. Journal of Public Economics 61: 359-381.

Cooper AC, Artz KW (1995) Determinants of satisfaction for entrepreneurs. Journal of Business Venturing 10: 439-457.

Crane R (1996) The influence of uncertain job location on urban form and the journey to work. Journal of Urban Economics 39: 342-356.

Crawley A (2014) The relationship between commuting time and workers' utility. Applied Economics Letters 21(18): 1273-1276.

Cropper M, Gordon P (1991) Wasteful commuting: a re-examination. Journal of Urban Economics 29: 2-13.

Cueto B, Pruneda, G (2015) Job Satisfaction of Wage and Self-Employed Workers. Do Job Preferences Make a Difference? Applied Research in Quality of Life 12(1): 103-123.

Dickerson A, Hole AR, Munford LA (2014) The relationship between well-being and commuting revisited: Does the choice of methodology matter? Regional Science and Urban Economics 49: 321-329.

Evans GW, Wener RE, Phillips D (2002) The morning rush hour: Predictability and commuter stress. Environment and behaviour 34(4): 521-530. 
Frey BS, Benz M, Stutzer A (2004) Introducing procedural utility: not only what, but also how matters. Journal of Institutional and Theoretical Economics 160: 377-401.

Garreau J (1991) Edge City: Life on the New Frontier. Doubleday, New York.

Giménez-Nadal, JI, Molina JA, Velilla, J (2017) Leisure and effort at work: incorporating selfemployment into urban markets. MPRA Paper 77972.

Giménez-Nadal JI, Molina JA, Velilla J (2018) The commuting behavior of workers in the United States: differences between the employed and the self-employed. Journal of transport geography 66: 19-29.

Giuliano G, Small AK (1993) Is the journey to work explained by urban structure? Urban Studies 30: 1485-1500.

Gottholmseder G, Nowotny K, Pruckner GJ, Theurl E (2009) Stress perception and commuting. Health Economics 18: 559-576.

Hamilton BW (1982) Wasteful commuting. Journal of Political Economy 90: 1035-1053.

Hämmig O, Gutzwiller F, Bauer G (2009) Work-life conflict and associations with work and nonwork-related factors and with physical and mental health outcomes : a national representative cross-sectional study in Switzerland. BMC Public Health 9: 435.

Hansson E, Mattisson K, Björk J, Östergren P, Jakobsson K (2011) Relationship between commuting and health outcomes in a cross-sectional population survey in southern Sweden. BMC Public Health 11: 834.

Holzer H.J (1994) Work, search and travel among white and black youth. Journal of Urban Economics 35: 320-345.

Huinink J, Feldhaus M (2012) Fertility and commuting behaviour in Germany. Comparative Population Studies 37: 3-4. 
Hundley, G (2001) Why and When Are the Self-Employed More Satisfied with Their Work? Industrial Relations 40(2): 293-316.

Jamal M (1997) Job stress, satisfaction, and mental health: an empirical examination of selfemployed and non-self-employed Canadians. Journal of Small Business Management 35(4): $48-57$.

Kahneman D, Krueger AB (2006) Developments in the Measurement of Subjective WellBeing. Journal of Economic Perspectives 20: 3-24.

Kahneman D, Krueger AB, Schkade DA, Schwarz N, Stone AA (2004) A Survey Method for Characterizing Daily Life Experience: The Day Reconstruction Method. Science 3: 1776-1780. Kim S (1995) Excess commuting for two-worker households in the Los Angeles metropolitan areas. Journal of Urban Economics 38: 166-182.

Koslowsky M, Kluger A, Reich M (2013) Commuting Stress: Causes, Effects and Methods of Coping (Springer Science \& Business Media) New York.

Knox PL, McCarthy L (2005) Urbanization: An Introduction to Urban Geography (Englewood Cliffs) Prentice Hall, New Jersey.

Krueger AB (1991) Ownership, agency and wages: an examination of franchising in the fast food industry. Quarterly Journal of Economics 106: 75-102.

Künn-Nelen A (2015) Does commuting affect health? Health economics 25: 984-1004.

Larsen MM, Pilegaard N, Van Ommeren J (2008) Congestion and residential moving behavior. Regional Science and Urban Economics 38(4): 378-387.

Lazear EP, Moore RL (1984) Incentives, productivity and labor contracts. Quarterly Journal of Economics 99: 275-296. 
Ma K R, Banister D (2006) Excess commuting: a critical review. Transport reviews 26(6): 749767.

MacKerron G (2012) Happiness economics from 35,000 feet. Journal of Economics Surveys 26 (4): 705-735.

Merriman D, Ohkawara T, Suzuki T (1995) Excess commuting in the Tokyo metropolitan area: measurement and policy simulations. Urban Studies 32: 69-85.

Mills ES (1972) Studies in the Structure of the Urban Economy (Johns Hopkins University Press) Baltimore.

Muller PO (1981) Contemporary Suburban America (Prentice Hall) New Jersey.

Muth RF (1969) Cities and Housing: The Spatial Pattern of Urban Residential Land Use (University of Chicago Press) Chicago.

Nguyen AN, Taylor J, Bradley S (2003) Job autonomy and job satisfaction: new evidence. Lancaster University Management School. Working Paper 2003/050.

Oaxaca R (1973) Male-Female Wage Differentials in Urban labor Markets. International Economic Review 14(3): 139-148.

Palomino J, Sarrias M (2019) The monetary subjective health evaluation for commuting long distances in Chile: A latent class analysis. Papers in Regional Science 1-21.

Roberts J, Hodgson R, Dolan P (2011) It's driving her mad: Gender differences in the effects of commuting on psychological health. Journal of Health Economics 30(5): 1064-1076.

Ross SL, Zenou Y (2008) Are shirking and leisure substitutable? An empirical test of efficiency wages based on urban economic theory. Regional Science Urban Economics 38(5): 498-51.

Rouwendal J (1998) Search theory, spatial labor markets, and commuting. Journal of Urban Economics 43: 1-22. 
Sandow E, Westerlund O, Lindgren U (2014) Is your commute killing you? On the mortality risks of long-distance commuting. Environment and Planning A 46(6): 1496-1516.

Sandow E (2013) Til work do us part: the social fallacy of long-distance commuting. Urban Studies 51(3): 526-543.

Simón H, Casado-Díaz JM, Lillo-Bañuls A (2018) Exploring the effects of commuting on workers' satisfaction: evidence for Spain. Regional Studies, forthcoming.

Stutzer A, Frey B S (2008) Stress that doesn't pay: The commuting paradox. The Scandinavian Journal of Economics 110(2): 339-366.

Van den Heuvel A, Wooden M (1997) Self-employed contractors and job satisfaction. Journal of Small Business Management 35(3): 11-20.

Van Ommeren J, Van Der Vlist A, Nijkamp P (2006) Transport-related fringe benefits: Implications for moving and the journey to work. Journal of Regional Science 46(3): 493-506.

Van Ommeren JN, Gutiérrez-i-Puigarnau E (2011) Are workers with a long commute less productive? An empirical analysis of absenteeism. Regional Science Urban Economics 41(1): $1-8$.

Van Ommeren JN, Van der Straaten JW (2008) The effect of search imperfections on commuting behaviour: Evidence from employed and self-employed workers. Regional Science and Urban Economics 38(2): 127-147.

Weinberg DH, Friedman J, Mayo SK (1981) Intraurban residential mobility: the role of transaction costs, market imperfections and household disequilibrium Journal of Urban Economics 9: 332-348.

Zax JS (1991) Compensation for commuters in labor and housing markets. Journal of Urban Economics 30: 192-207. 
Table 1. Determinants of commuting. OLS.

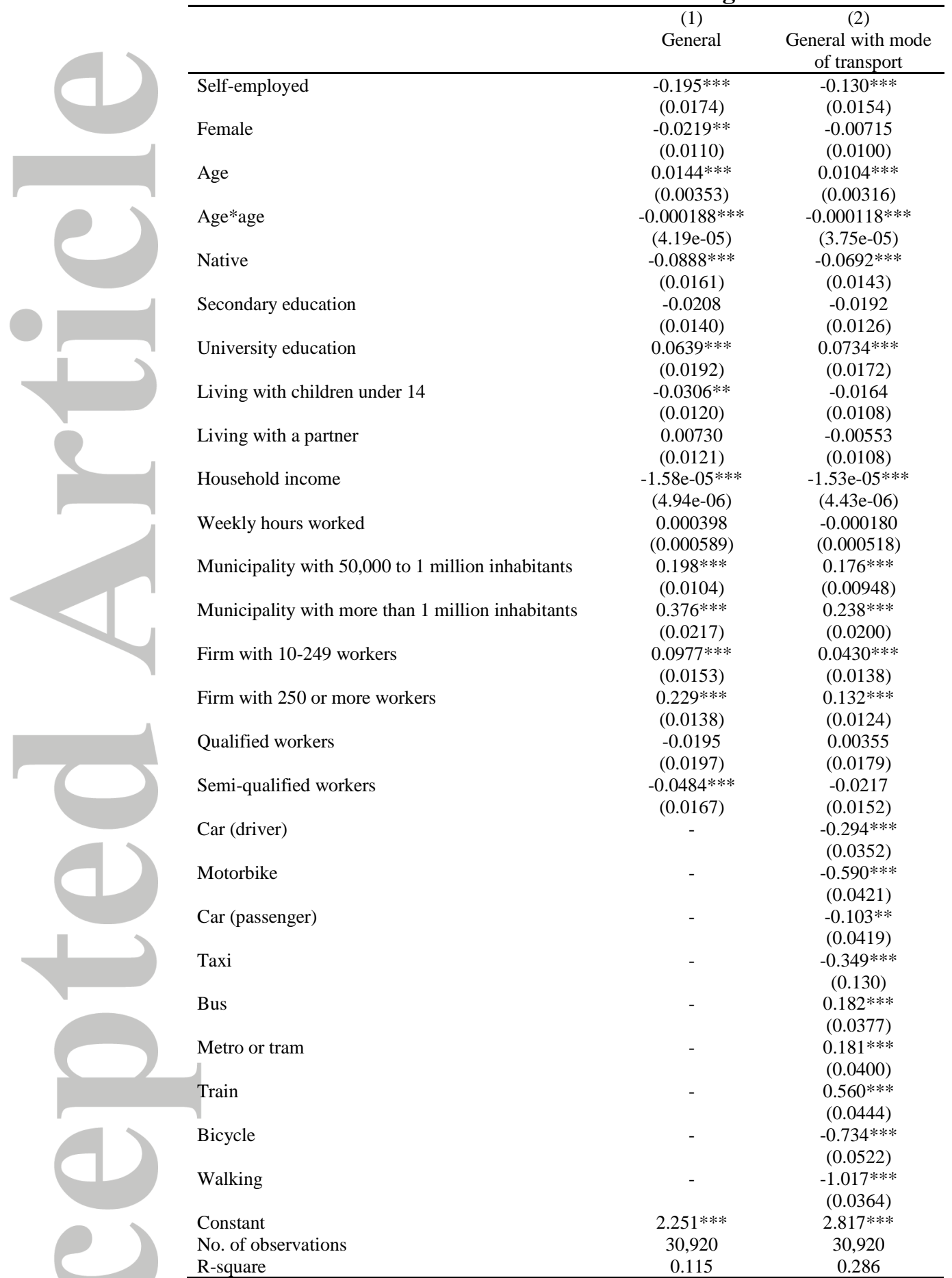

Notes: All estimated models consider year and region fixed effects, and sector of occupation. Robust standard errors in brackets. *** $\mathrm{p}<0.01 * * \mathrm{p}<0.05 * \mathrm{p}<0.1$ 
Table 2. Determinants of commuting. Alternative disaggregate estimations by size of municipality and level of qualification. OLS.

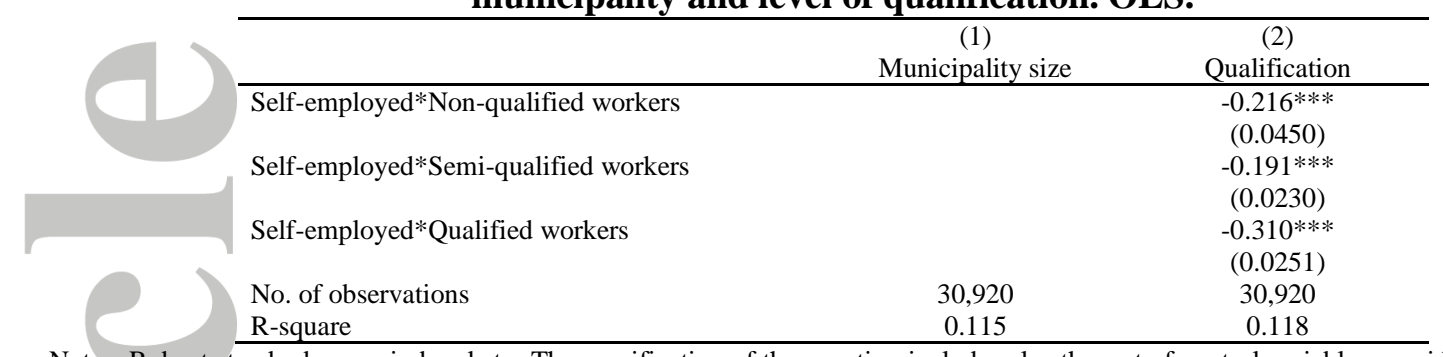

Notes: Robust standard errors in brackets. The specification of the equation includes also the rest of control variables considered in column (1) of Table 1.
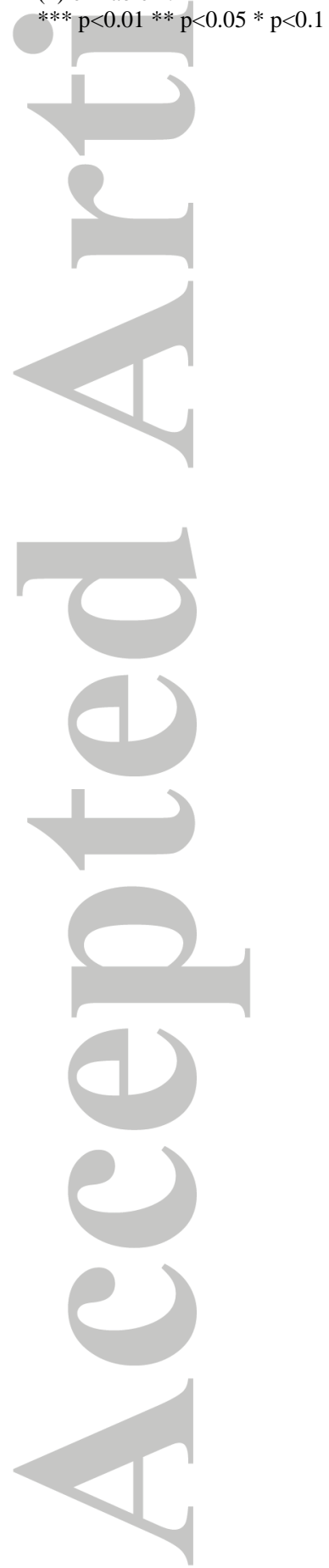

This article is protected by copyright. All rights reserved. 
Table 3. Decomposition of differences in commuting between employees and self-employed workers. Oaxaca-Blinder methodology.

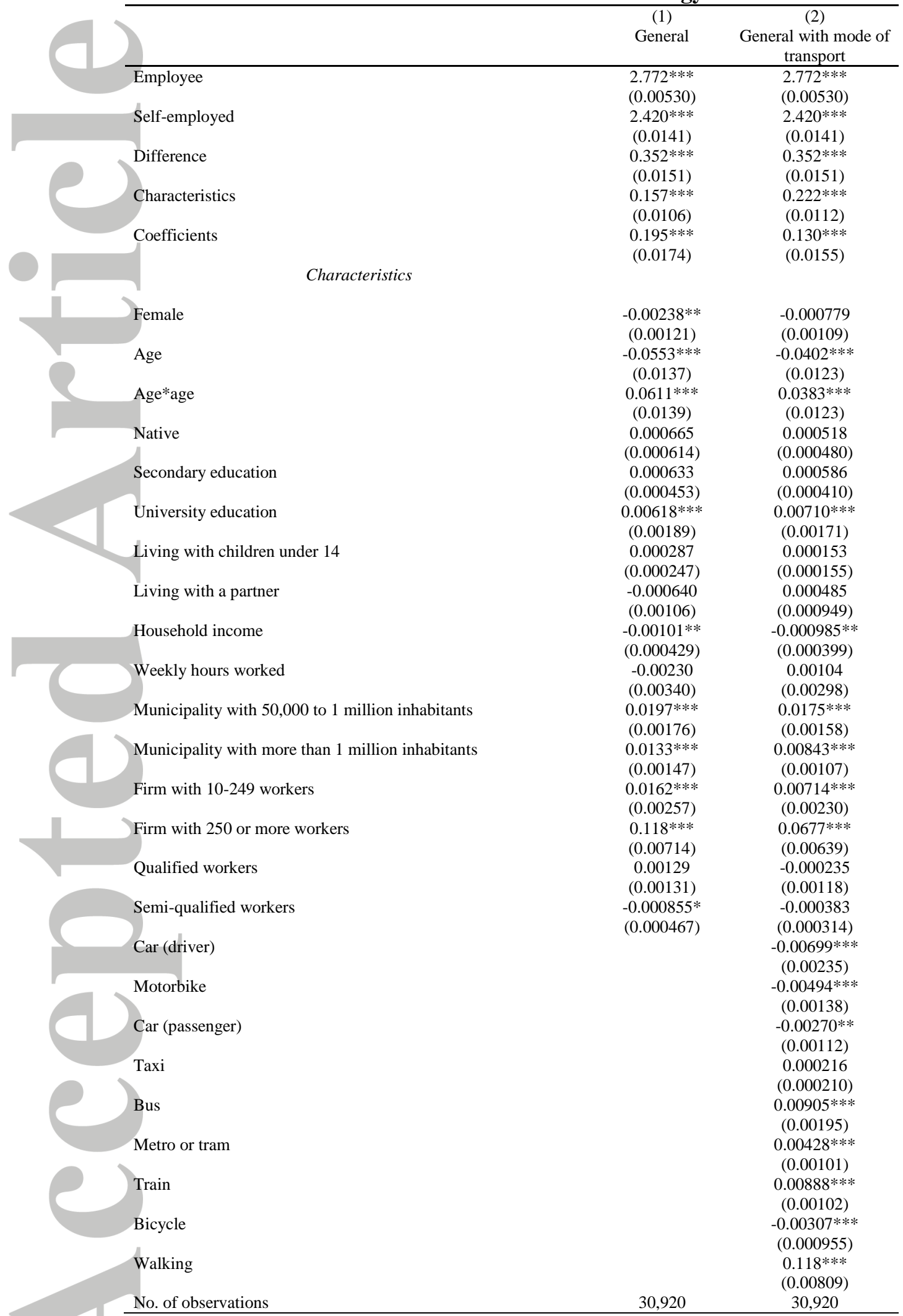

Notes: Both estimated models consider year and region fixed effects, sector and occupation. Robust standard errors in brackets. $* * * \mathrm{p}<0.01 * * \mathrm{p}<0.05 * \mathrm{p}<0.1$ 
Table 4. Determinants of commuting. Instrumental variables.

\begin{tabular}{lc}
\hline & $(1)$ \\
& Instrumental variables \\
\hline Self-employed & -0.0782 \\
& $(0.0655)$ \\
No. of observations & 30,920 \\
& \\
R-square & 0.114 \\
$\quad$ Strong instrument and endogeneity tests & $1499.49^{* * *}$ \\
Partial F-Statistic & $3.5102^{*}$ \\
Durbin/ GMM C x2 & $3.5052^{*}$ \\
Wu-Hausman & \\
\hline
\end{tabular}

Notes: Robust standard errors in brackets. The specification of the equation includes also the rest of control variables considered in column (1) of Table 1. The instrument considered in the estimation corresponds to vocational entrepreneurship. $* * * \mathrm{p}<0.01 * * \mathrm{p}<0.05 * \mathrm{p}<0.1$

Table 5. Determinants of job and housing satisfaction. Ordered logit.

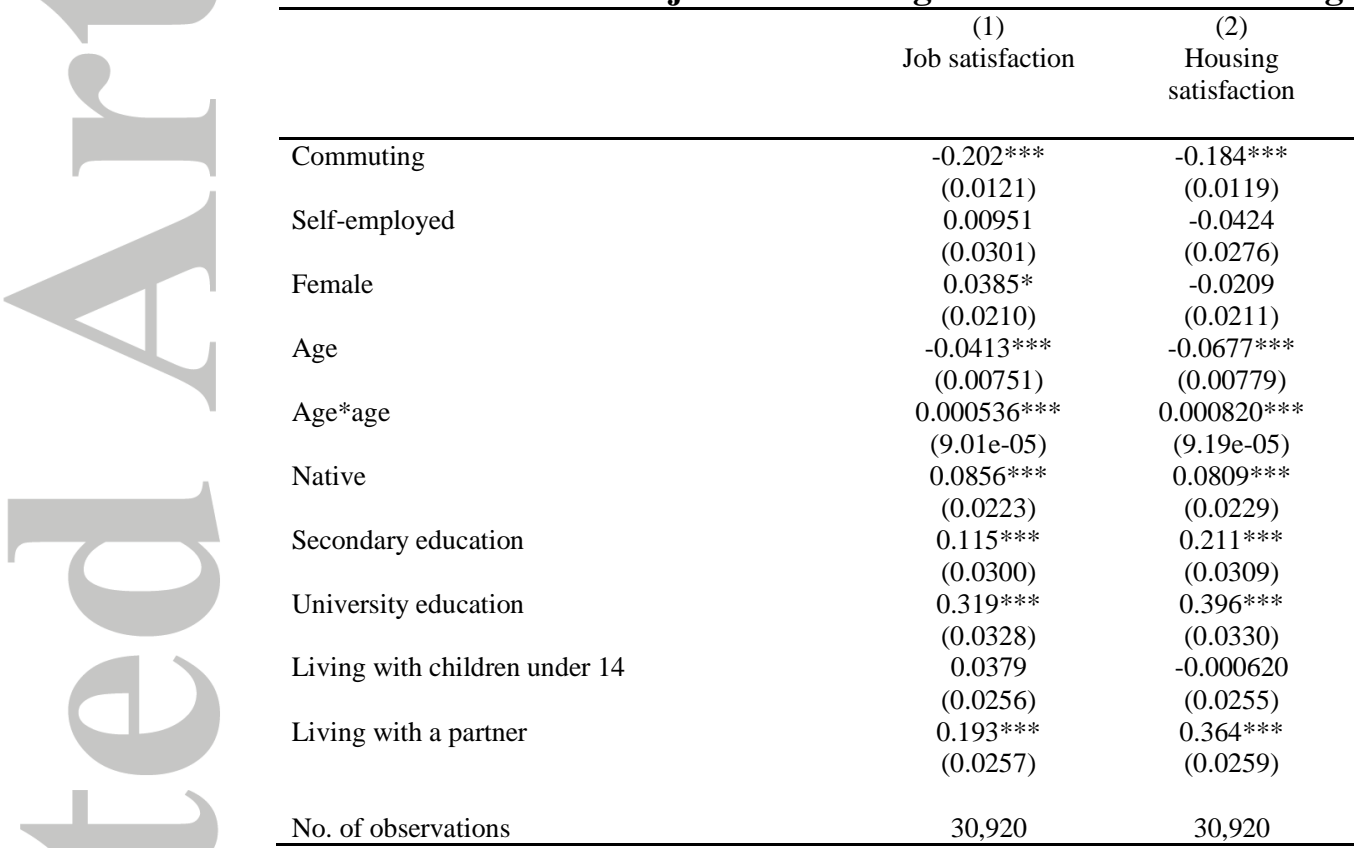

Notes: Both estimated models consider year and region fixed effects, sector and occupation. Robust standard errors in brackets. $* * * \mathrm{p}<0.01 * * \mathrm{p}<0.05 * \mathrm{p}<0.1$ 
Table 6. Determinants of job and housing satisfaction. Disaggregated estimations for employees and self-employed workers. Ordered logit.

\begin{tabular}{|c|c|c|c|c|}
\hline & \multicolumn{2}{|c|}{ Self-employed } & \multicolumn{2}{|c|}{ Employees } \\
\hline & $(1)$ & (2) & (3) & $(4)^{*}$ \\
\hline & Job* & Housing* & $\mathrm{Job}^{*}$ & Housing* \\
\hline Commuting & $-0.09908^{* * * *}$ & $-0.11583^{* * *}$ & $-0.23517 * * *$ & $-0.20678 * * *$ \\
\hline 1 & $(0.02441)$ & $(0.02427)$ & $(0.01374)$ & $(0.01360)$ \\
\hline No. of observations & 5,400 & 5,400 & 25,520 & 25,520 \\
\hline
\end{tabular}

Notes: Robust standard errors in brackets. The specification of the equation includes also the rest of control variables considered in Table 5.

$* * * \mathrm{p}<0.01 * * \mathrm{p}<0.05 * \mathrm{p}<0.1$

Table 7. Determinants of job satisfaction. Ordered logit. Alternative disaggregate estimations by size of municipality and level of qualification. Self-employed. Ordered logit.

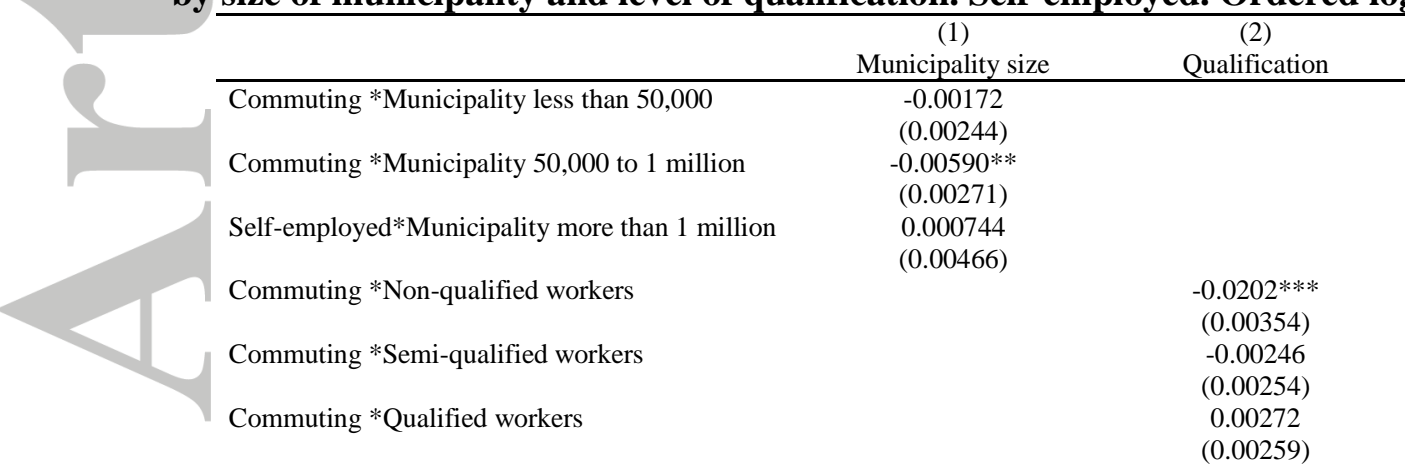

Notes: Robust standard errors in brackets. The specification of the equation includes also the rest of control variables considered in Table 5 .

$* * * \mathrm{p}<0.01 * * \mathrm{p}<0.05 * \mathrm{p}<0.1$

Table 8. Determinants of housing satisfaction. Ordered logit. Alternative disaggregate estimations by size of municipality and level of qualification. Self-employed. Ordered logit.

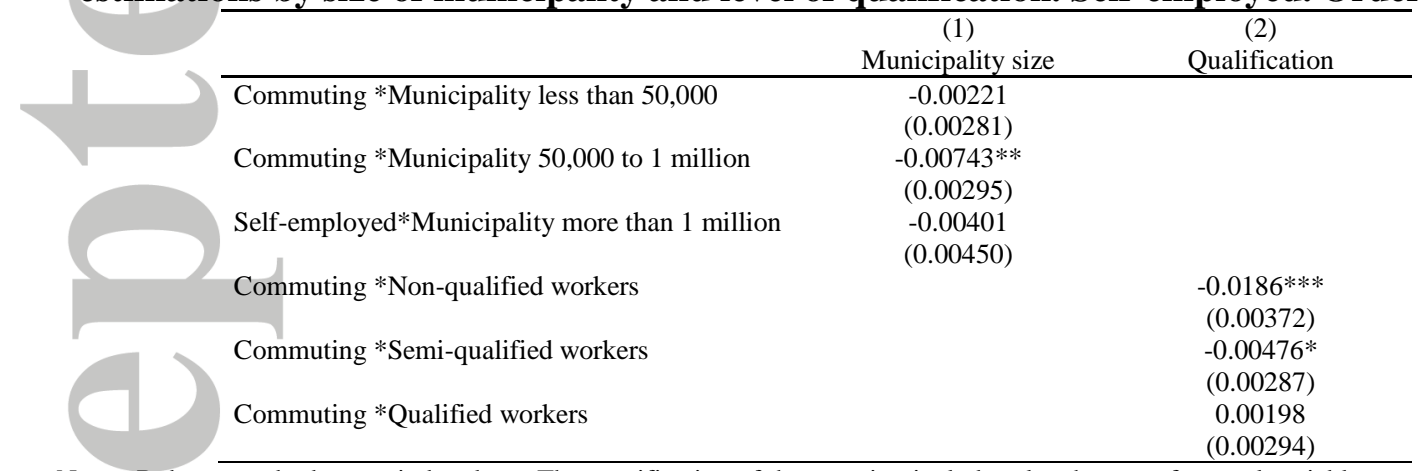

Notes: Robust standard errors in brackets. The specification of the equation includes also the rest of control variables considered in Table *** $\mathrm{p}<0.01 * * \mathrm{p}<0.05 * \mathrm{p}<0.1$

This article is protected by copyright. All rights reserved. 


\section{Appendix}

\begin{tabular}{|c|c|c|c|c|}
\hline \multicolumn{5}{|c|}{ Table A.1. Descriptives. } \\
\hline & \multicolumn{2}{|c|}{ SELF-EMPLOYED } & \multicolumn{2}{|c|}{ EMPLOYED } \\
\hline COMMUTING (TIME IN & $\begin{array}{c}\text { Mean } \\
17.892\end{array}$ & $\begin{array}{c}\text { S.D. } \\
18.403\end{array}$ & $\begin{array}{c}\text { Mean } \\
22.156\end{array}$ & $\begin{array}{c}S . D . \\
19.018\end{array}$ \\
\hline MINUTES) & & & & \\
\hline COMMUTING LOG & 2.420 & 1.036 & 2.772 & 0.847 \\
\hline SATISFACTION (0-10 SCALE) & & & & \\
\hline JOB SATISFACTION & 7.320 & 1.917 & 7.285 & 1.740 \\
\hline HOUSING SATISFACTION & 7.757 & 1.684 & 7.726 & 1.709 \\
\hline FEMALE & 0.331 & 0.471 & 0.440 & 0.496 \\
\hline AGE & 45.09 & 10.364 & 41.245 & 10.675 \\
\hline NATIVE & 0.715 & 0.452 & 0.707 & 0.455 \\
\hline $\begin{array}{l}\text { LIVING WITH CHILDREN } \\
\text { UNDER } 14\end{array}$ & 0.361 & 0.480 & 0.351 & 0.477 \\
\hline LIVING WITH A PARTNER & 0.747 & 0.435 & 0.659 & 0.474 \\
\hline EDUCATION & & & & \\
\hline PRIMARY EDUCATION & 0.249 & 0.433 & 0.183 & 0.387 \\
\hline SECONDARY EDUCATION & 0.580 & 0.494 & 0.549 & 0.498 \\
\hline UNIVERSITY EDUCATION & 0.170 & 0.375 & 0.266 & 0.442 \\
\hline WEEKLY HOURS WORKED & 44.654 & 13.369 & 38.890 & 8.665 \\
\hline HOUSEHOLD INCOME (€) & 1926.3 & 1237.7 & 1990.5 & 1139.5 \\
\hline VOCATIONAL & 0.628 & 0.483 & 0.222 & 0.416 \\
\hline ENTREPRENEURSHIP & & & & \\
\hline OCCUPATION & & & & \\
\hline QUALIFIED WORKERS & 0.409 & 0.492 & 0.342 & 0.475 \\
\hline $\begin{array}{l}\text { SEMI-QUALIFIED } \\
\text { WORKERS }\end{array}$ & 0.511 & 0.500 & 0.529 & 0.499 \\
\hline NON-QUALIFIED & & & & \\
\hline WORKERS & 0.080 & $0.2 / 2$ & 0.129 & 0.335 \\
\hline FIRM SIZE & & & & \\
\hline < 10 WORKERS & 0.910 & 0.286 & 0.230 & 0.421 \\
\hline 10-249 WORKERS & 0.057 & 0.231 & 0.223 & 0.416 \\
\hline 250 OR MORE WORKERS & 0.033 & 0.179 & 0.547 & 0.498 \\
\hline SECTOR OF ACTIVITY & & & & \\
\hline FARMING & 0.139 & 0.346 & 0.032 & 0.176 \\
\hline MANUFACTURING & 0.096 & 0.294 & 0.168 & 0.374 \\
\hline CONSTRUCTION & 0.154 & 0.361 & 0.113 & 0.316 \\
\hline COMMERCE & 0.207 & 0.405 & 0.122 & 0.327 \\
\hline TRANSPORT & 0.062 & 0.241 & 0.052 & 0.221 \\
\hline HOSPITALITY & 0.076 & 0.264 & 0.060 & 0.237 \\
\hline INFO AND & 0.012 & 0.111 & 0.022 & 0.145 \\
\hline $\begin{array}{l}\text { COMMUNICATION } \\
\text { FINANCIAL AND REAL }\end{array}$ & & & & \\
\hline ESTATE & 0.024 & 0.152 & 0.032 & 0.176 \\
\hline $\begin{array}{l}\text { PROFESSIONAL AND } \\
\text { SCIENTIFIC }\end{array}$ & 0.081 & 0.272 & 0.059 & 0.236 \\
\hline $\begin{array}{l}\text { ADMINISTRATION AND } \\
\text { AUXILIARY }\end{array}$ & 0.016 & 0.124 & 0.035 & 0.183 \\
\hline SOCIAL SERVICES & 0.042 & 0.202 & 0.262 & 0.440 \\
\hline OTHERS SERVICES & 0.092 & 0.289 & 0.044 & 0.205 \\
\hline MUNICIPALITY SIZE & & & & \\
\hline$<50,000$ INHABITANTS & 0.602 & 0.489 & 0.468 & 0.499 \\
\hline 50,000 - 1 MILLION & 0.351 & 0.477 & 0.450 & 0.498 \\
\hline > 1 MILLION & 0.047 & 0.211 & 0.082 & 0.275 \\
\hline TRANSPORT MODE & & & & \\
\hline PASSIVE TRANSPORT & 0.067 & 0.250 & 0.182 & 0.386 \\
\hline ACTIVE TRANSPORT & 0.933 & 0.250 & 0.818 & 0.386 \\
\hline CAR DRIVER & 0.543 & 0.498 & 0.567 & 0.495 \\
\hline MOTORCYCLE & 0.022 & 0.147 & 0.030 & 0.172 \\
\hline PASSENGER CAR & 0.017 & 0.129 & 0.043 & 0.203 \\
\hline TAXI & 0.001 & 0.038 & 0.001 & 0.029 \\
\hline BUS & 0.029 & 0.169 & 0.079 & 0.270 \\
\hline METRO & 0.014 & 0.118 & 0.038 & 0.191 \\
\hline TRAIN & 0.005 & 0.072 & 0.021 & 0.144 \\
\hline BICYCLE & 0.006 & 0.080 & 0.011 & 0.103 \\
\hline WALKING & 0.313 & 0.464 & 0.197 & 0.398 \\
\hline OTHER & 0.048 & 0.213 & 0.013 & 0.113 \\
\hline
\end{tabular}

Source: Own elaboration from Survey of Quality of Life at Work. 
Table A.2. Determinants of commuting. Alternative estimations including individuals working from home.

\begin{tabular}{|c|c|c|c|c|}
\hline & \multicolumn{2}{|c|}{ Excluding individuals working from home } & \multicolumn{2}{|c|}{ Including individuals working from home } \\
\hline & (1) & $(2)$ & (3) & (4) \\
\hline & General & $\begin{array}{c}\text { General with } \\
\text { mode of transport }\end{array}$ & General & $\begin{array}{c}\text { General with } \\
\text { mode of transport }\end{array}$ \\
\hline Self-employed & $-3.131 * * *$ & $-1.347 * * *$ & $-1.892 * * *$ & $-0.618 * * *$ \\
\hline & $(0.331)$ & $(0.311)$ & $(0.342)$ & $(0.317)$ \\
\hline No. of observations & 32,019 & 32,019 & 30,920 & 30,920 \\
\hline
\end{tabular}

Notes: Robust standard errors in brackets. The specification of the equation includes also the rest of control variables considered in columns (1) and (4) of Table 1. Commuting is measured in minutes.

$* * * \mathrm{p}<0.01 * * \mathrm{p}<0.05 * \mathrm{p}<0.1$

Table A.3. Determinants of job and housing satisfaction. Robustness test including additional variables. Ordered logit.

\begin{tabular}{|c|c|c|}
\hline & $\begin{array}{c}(1) \\
\text { Job satisfaction }\end{array}$ & $\begin{array}{c}(2) \\
\text { Housing satisfaction }\end{array}$ \\
\hline Commuting & $-0.190 * * *$ & $-0.162 * * *$ \\
\hline & $(0.0127)$ & $(0.0124)$ \\
\hline \multirow[t]{2}{*}{ Self-employed } & 0.0417 & 0.00117 \\
\hline & $(0.0364)$ & $(0.0348)$ \\
\hline \multirow[t]{2}{*}{ Female } & -0.0311 & 0.0171 \\
\hline & $(0.0232)$ & $(0.0231)$ \\
\hline \multirow[t]{2}{*}{ Age } & $-0.0349 * * *$ & $-0.0623 * * *$ \\
\hline & $(0.00757)$ & $(0.00782)$ \\
\hline \multirow{2}{*}{ Age*age } & $0.000455^{* * *}$ & $0.000757 * * *$ \\
\hline & $(9.08 \mathrm{e}-05)$ & $(9.23 \mathrm{e}-05)$ \\
\hline \multirow[t]{2}{*}{ Native } & $-0.120 * * *$ & $0.292 * * *$ \\
\hline & $(0.0366)$ & $(0.0387)$ \\
\hline \multirow[t]{2}{*}{ Secondary education } & $-0.0523^{*}$ & $0.100 * * *$ \\
\hline & $(0.0313)$ & $(0.0322)$ \\
\hline \multirow[t]{2}{*}{ University education } & $-0.179 * * *$ & 0.0345 \\
\hline & $(0.0413)$ & $(0.0411)$ \\
\hline \multirow[t]{2}{*}{ Living with children under 14} & 0.0295 & 0.00881 \\
\hline & $(0.0256)$ & $(0.0256)$ \\
\hline \multirow[t]{2}{*}{ Living with a partner } & $0.0915 * * *$ & $0.235^{* * *}$ \\
\hline & $(0.0264)$ & $(0.0266)$ \\
\hline \multirow[t]{2}{*}{ Household income } & $0.000156^{* * * *}$ & $0.000212 * * *$ \\
\hline & $(9.96 \mathrm{e}-06)$ & $(9.80 \mathrm{e}-06)$ \\
\hline \multirow[t]{2}{*}{ Weekly hours worked } & $-0.00694 * * *$ & -0.000569 \\
\hline & $(0.00131)$ & $(0.00123)$ \\
\hline \multirow[t]{2}{*}{ Municipality with 50,000 to 1 million inhabitants } & $-0.111 * * *$ & $-0.144 * * *$ \\
\hline & $(0.0221)$ & $(0.0221)$ \\
\hline \multirow[t]{2}{*}{ Municipality with more than 1 million inhabitants } & $-0.278 * * *$ & $-0.400 * * *$ \\
\hline & $(0.0452)$ & $(0.0474)$ \\
\hline \multirow[t]{2}{*}{ Firm with $10-249$ workers } & -0.00728 & 0.0511 \\
\hline & $(0.0330)$ & $(0.0337)$ \\
\hline \multirow{2}{*}{ Firm with 250 or more workers } & -0.0376 & $0.0547 *$ \\
\hline & $(0.0296)$ & $(0.0307)$ \\
\hline \multirow[t]{2}{*}{ Qualified workers } & $0.539 * * *$ & $0.317 * * *$ \\
\hline & $(0.0438)$ & $(0.0433)$ \\
\hline \multirow[t]{2}{*}{ Semi-qualified workers } & $0.346^{* * *}$ & $0.234 * * *$ \\
\hline & $(0.0388)$ & $(0.0387)$ \\
\hline No. of observations & 30,920 & 30,920 \\
\hline
\end{tabular}

Notes: Both estimated models consider year and region fixed effects, sector and occupation. Robust standard errors in brackets. $* * * \mathrm{p}<0.01 * * \mathrm{p}<0.05 * \mathrm{p}<0.1$

Table A.4. Determinants of job and housing satisfaction. Alternative estimations including individuals working from home.

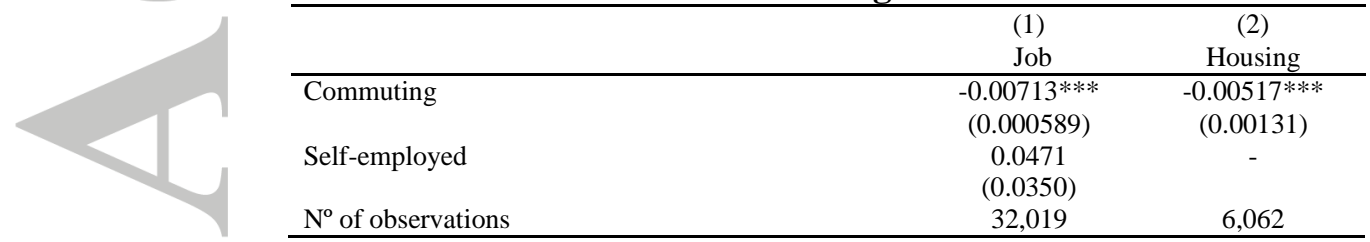

Notes: Robust standard errors in brackets. The specification of the equation includes also the rest of control variables considered in Table 5 . Commuting is measured in minutes.

$* * * \mathrm{p}<0.01 * * \mathrm{p}<0.05 * \mathrm{p}<0.1$ 